\title{
Deaths from asphyxiation and poisoning at work in the United States 1984-6
}

\author{
A SURUDA, J AGNEW \\ From the Division of Occupational Medicine, Department of Environmental Health Sciences, Johns Hopkins \\ University School of Hygiene and Public Health, Baltimore, Maryland, USA
}

\begin{abstract}
A review of 4756 deaths investigated by the Occupational Safety and Health Administration (OSHA) in 1984-6 found 233 deaths from asphyxiation and poisoning, excluding asphyxiations from trench cave-ins. The highest rates were in the oil and gas industry and in utilities. Toxic gases were the largest group (65) followed by simple asphyxiants (48), mechanical causes (42), and solvents (35). Deaths from solvents were significantly more likely in young workers. Nine deaths were caused by improper air supply to respirators and five by recreational inhalation of gas or vapours. Of the 146 deaths in confined spaces, only $12 \%$ were in rescuers, fewer than previously reported.
\end{abstract}

Air unsuitable for breathing has long been recognised as an occupational health hazard. The Roman emperor Trajan punished certain offenders by appointing them to clean sewers, a job considered one of the worst.' ${ }^{\prime}$ Fifty years ago, gas poisoning was considered a "frequent hazard of industrial life." Although asphyxiation in specific industries such as steel was examined early in this century, ${ }^{3}$ there have been few population based studies of deaths due to this problem.

In the United States the Bureau of Labor Statistics (BLS) Annual Survey of Occupational Injuries and Illnesses reports deaths from 14 different causes. For 1984 , of the 3740 work related deaths in the private sector reported by the BLS, 3\% were due to gas inhalation and $4 \%$ from "all other causes" other than heart attacks and trauma. ${ }^{4}$ For 1985 , the National Center for Health Statistics (NCHS) reported 700 deaths in the United States from poisoning by gases and vapours, mostly carbon monoxide, ${ }^{5}$ but did not indicate the proportion of these which were work related. An unpublished internal study by the Occupational Safety and Health Administration (OSHA) of all deaths investigated over a 44 month period from May 1974 to December 1977 reported that of the 5793 deaths investigated, 561 were due to asphyxiation or poisoning, or $\mathbf{9 . 7 \%}$ of all deaths that were investigated during this period; these included both mechanical and chemical asphyxiations (printout provided by W Cloe, OSHA, 1978).

In Sweden of the 767 deaths classified as "occupational accidents" in 1979-83, only 10 were reportedly due to contact with a chemical agent. ${ }^{6}$ There were 25 deaths listed from "miscellaneous causes" and the remaining 732 were from trauma. The Swedish report did not list a separate category for asphyxiation.

In Malaysia 485 work related deaths were reported to the workers compensation and social security system for 1983 . Forty three $(8 \cdot 8 \%)$ were due to asphyxiation or poisoning. ${ }^{\text {? }}$

A study of fatal injuries in Britain during maintenance activities in manufacturing and service industries in 1980-2 reported that $24(7 \cdot 4 \%)$ of the 326 deaths in this category were due to asphyxiation or gas inhalation. ${ }^{8}$ Maintenance deaths made up $21 \%$ of all deaths reported to the Health and Safety Executive during this period. Other British studies have examined injury from specific substances. Bakinson and Jones reviewed 118 cases, including four deaths, of gassing due to methylene chloride, xylene, toluene, and styrene reported to the Factory Inspectorate, the predecessor of the Health and Safety Executive, from 1961 to $1980 .{ }^{9}$ When the cases were stratified by whether or not the victim had lost consciousness, younger workers appeared to be more severely affected.

Also in Britain McCarthy and Jones made a similar analysis of 384 cases in 1961-80, of which 17 were fatal, caused by trichloroethylene, perchloroethylene, and 1-1-1 trichloroethane. ${ }^{10}$ Younger workers were again found to be more vulnerable and in nine cases deliberate inhalation of solvents was suspected. Toxicity was attributed to the effects of these solvents on the central nervous system. 
In the present study the OSHA Integrated Management Information System (IMIS) database was searched for all deaths in 1984-6 investigated by OSHA and in which asphyxiation or poisoning was implicated in an attempt to discover the extent of these deaths in the United States and the chemical substances and other factors involved.

OSHA offices investigate all reported work related deaths for which OSHA has jurisdiction. Mining, transportation, maritime, federal employees, and certain other groups are regulated by other agencies. Farms with fewer than 11 employees are exempt from OSHA regulation.

OSHA obtains death reports from employers, the media, and local health officials. A study in Pennsylvania in $1983-4$ found that only $50-60 \%$ of all occupational traumatic deaths were within OSHA jurisdiction. ${ }^{1}$ In Colorado the State Department of Health found that OSHA learnt of only $65 \%$ of the work related deaths in 1982-4 for which OSHA had jurisdiction. $^{12}$ OSHA offices do not investigate homicides, suicides, or motor vehicle accident deaths.

\section{Methods}

A printout was obtained of all deaths for the years 1984-6 from the OSHA IMIS database. This database contains information on all accidents investigated by OSHA in 47 states. These states comprise $83 \%$ of the United States workforce. ${ }^{13}$ California, Washington State, and Michigan have state OSHA plans that maintain datafiles not compatible with the federal system. The OSHA IMIS database contains descrip- tive information about the employer and injured employee and a written abstract concerning the chcumstances of injury.

OSHA death investigations are coded according "nature of injury," for which a list of 22 items js available for the investigating officer to choose frof All deaths coded "asphyxiation" or "poisoning" we selected for this study. In addition, the abstract of every death in the database for 1984-6 was reviewed? detect coding errors.

One death coded as an asphyxiation was excludegd from this series. This was in a worker who was struck in the chest by a $3000 \mathrm{lb}$ steel beam and crusheg. Mechanical asphyxiations due to being buried di materials such as in grain elevators or sand bins wege included.

\section{Results}

For the period 1984-6, 4756 deaths were reported in the OSHA IMIS database for 47 states. Of these, 423 $(8.9 \%)$ were due to asphyxiation or poisoning. The 190 asphyxiations that occurred in trench cave-ins have been described elsewhere and will not be disct sed further. ${ }^{14}$ For the remaining 233 cases, a list of the agents which caused death is shown in table 1 . The?e were 42 deaths from mechanical causes such as being buried alive in a grain bin, seven in which the repoit was incomplete and the code for the agent causing the death was missing, 48 were due to simple asphyxianiss such as argon or nitrogen, and 27 from oxpen deficient air in which a specific substance was not reported. Of the remaining 109 deaths, 65 were due

Table 1 Causes of asphyxiation and poisoning in death investigations in the OSHA IMIS database, $1984-6$

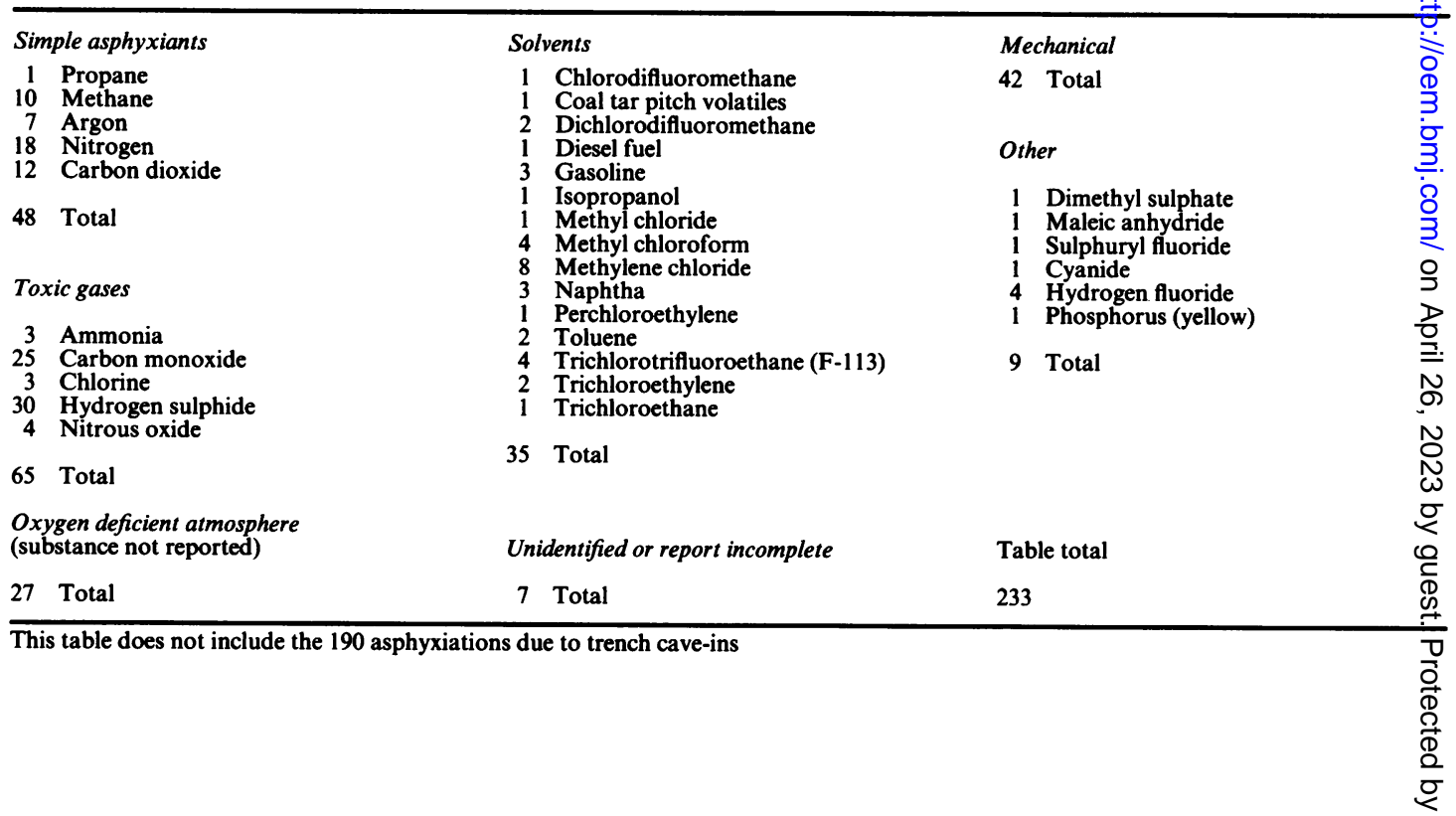


toxic gases, 35 to solvents, and nine to other poisonous agents. Air sampling data related to the incident was not available from the database, nor were details of first aid or emergency medical treatment.

These 233 deaths occurred in 198 separate events. There were 78 deaths in 1984, 76 in 1985, and 79 in 1986. Fifty three $(23 \%)$ were in firms covered by a collective bargaining agreement with a union.

Only two of the deaths were in women, in similar incidents at different plants. Both occurred when the employee fell into a degreasing tank while attempting to retrieve a printed circuit board.

The age was known for 222 of 233 deaths. The mean age was 34.2 years, with a standard deviation of 12.5 (figure). Workers killed by solvents were significantly younger than the others $(p<0.01)$, with a mean age of 29.0 years.

\section{INDUSTRY}

The largest number of deaths was in manufacturing

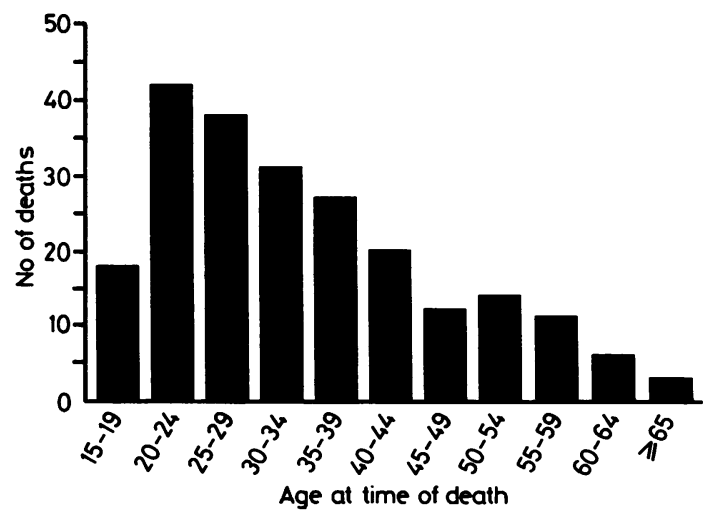

Age at death for 222 victims of asphyxiation and poisoning, 1984-6. (Age was unknown for one victim.)
$(38 \%)$, followed by trade (14\%), construction ( $12 \%)$, and the oil and gas industry (11\%) (table 2). The highest rates for asphyxiation and poisoning were seen in the oil and gas industry and in utilities. In these industries the primary substances were hydrogen sulphide, present in sewers, manholes, and oil field fracturing tanks, and gaseous hydrocarbons such as methane.

\section{MECHANICAL ASPHYXIATIONS}

These $\mathbf{4 2}$ deaths occurred in grain elevators or grain bins (12), storage bins (8), railroad cars (5), sand hoppers (4), dump trucks (2), and other (11). Grain bins and elevators, sand hoppers, and storage bins were implicated in $24(57 \%)$ deaths. In 13 the employee was standing in a bin on top of sand or grain in which a void or cavity existed that had been "bridged." When the bridge collapsed the employee fell into the material and was suffocated. Ten other deaths occurred when an employee fell into a bin and was buried in loose material.

\section{CONFINED SPACES}

Of the remaining 184 deaths, excluding the 42 mechanical asphyxiations and the seven cases with incomplete information, $146(79 \%)$ occurred in confined spaces. According to OSHA, a confined space is "an enclosed or partially enclosed work space that has limited means of entry and exit, which may be subject to accumulations of toxic or flammable contaminants, or where an oxygen deficiency may develop."15

Of the 146 deaths in confined spaces, 17 (12\%) were in coworkers or emergency personnel attempting to rescue a worker who had become unconscious. In 16 of these the rescue was attempted without the use of self contained breathing apparatus, and in one the SCBA ran out of air. Two of the 17 deaths were police officers who responded to a distress call in an incident at a sewage treatment plant.

ıble 2 Cause of asphyxiation by industry group

\begin{tabular}{|c|c|c|c|c|c|c|c|c|c|c|}
\hline & $\begin{array}{l}\text { Mech- } \\
\text { anical }\end{array}$ & $\begin{array}{l}\text { Simple } \\
\text { asphyxiants }\end{array}$ & $\begin{array}{l}\text { Toxic } \\
\text { gases }\end{array}$ & $\begin{array}{l}\text { Oxygen def } \\
\text { substance } \\
\text { not reported }\end{array}$ & Solvents & Other & $\begin{array}{l}\text { Report } \\
\text { incomplete }\end{array}$ & Total & $\begin{array}{l}1984 \\
\text { employment } \\
\text { (thousands) }\end{array}$ & $\begin{array}{l}\text { Rate/ } \\
\text { million } \\
\text { workers }\end{array}$ \\
\hline $\begin{array}{l}\text {;riculture } \\
\text { instruction } \\
\text { l/gas } \\
\text { inufacturing } \\
\text { vices } \\
\text { ade, wholesale and } \\
\text { etail }\end{array}$ & $\begin{array}{r}3 \\
3 \\
1 \\
20 \\
1 \\
10\end{array}$ & $\begin{array}{r}0 \\
6 \\
8 \\
26 \\
2 \\
1\end{array}$ & $\begin{array}{r}0 \\
4 \\
11 \\
13 \\
7 \\
12\end{array}$ & $\begin{array}{l}0 \\
8 \\
4 \\
7 \\
2 \\
4\end{array}$ & $\begin{array}{r}0 \\
6 \\
2 \\
11 \\
5 \\
5\end{array}$ & $\begin{array}{l}1 \\
0 \\
0 \\
6 \\
1 \\
0\end{array}$ & $\begin{array}{l}0 \\
0 \\
0 \\
5 \\
1 \\
1\end{array}$ & $\begin{array}{r}4 \\
27 \\
26 \\
88 \\
19 \\
33\end{array}$ & $\begin{array}{c}933 \cdot 8 \\
4345 \\
612 \cdot 7 \\
19412 \\
20761 \\
22134\end{array}$ & $\begin{array}{r}1 \cdot 68 \\
2 \cdot 44 \\
16 \cdot 64 \\
1 \cdot 78 \\
0.36 \\
0.58\end{array}$ \\
\hline $\begin{array}{l}\text { ansport } \\
\text { ilities } \\
\text { her }\end{array}$ & $\begin{array}{l}3 \\
1 \\
0\end{array}$ & $\begin{array}{l}1 \\
4 \\
0\end{array}$ & $\begin{array}{l}3 \\
7 \\
8\end{array}$ & $\begin{array}{l}1 \\
0 \\
1\end{array}$ & $\begin{array}{l}5 \\
0 \\
1\end{array}$ & $\begin{array}{l}1 \\
0 \\
0\end{array}$ & $\begin{array}{l}\mathbf{0} \\
\mathbf{0} \\
\mathbf{0}\end{array}$ & $\begin{array}{l}14 \\
12 \\
10\end{array}$ & $\begin{array}{r}2673 \cdot 1 \\
898 \cdot 9 \\
7213 \cdot 3\end{array}$ & $\begin{array}{l}2 \cdot 05 \\
5 \cdot 24 \\
0 \cdot 54\end{array}$ \\
\hline tal & 42 & 48 & 65 & 27 & 35 & 9 & 7 & 233 & $78983 \cdot 8$ & $1 \cdot 16$ \\
\hline
\end{tabular}

iployment data taken from the 1984 Bureau of Labor Statistics Survey of Occupational Injuries and Illnesses. (Rates are adjusted for data from 47 states.) 
The types of confined spaces were varied and included vats, tanks, reactor vessels, ship holds, and other unventilated areas. The largest single group was sewers and manholes, with 31 deaths $(21 \%)$. In this group, with the exception of a single incident involving a chlorine leak that killed three workers, these deaths had similar circumstances - namely, the entry of an unprepared worker into an unventilated space below ground level.

The OSHA IMIS database contains coding for only one chemical or physical substance per death report; the coding for the deaths in sewers and manholes was: oxygen deficiency, no specific substance noted (14), hydrogen sulphide (8), carbon monoxide (3), chlorine (3), methane (2), and other (1).

\section{CARBON MONOXIDE}

Of the 25 deaths through carbon monoxide, six were due to faulty pumps and compressors and five to vehicles operated indoors in areas with insufficient ventilation. Faulty space heaters caused four deaths and gases from industrial furnaces two. Six deaths were from other sources and two had no descriptive information of the source of $\mathrm{CO}$.

\section{HYDROGEN SULPHIDE}

There were 30 deaths involving $\mathrm{H}_{2} \mathrm{~S}$. Eight were in sewers or manholes and nine in fracturing tanks or pits containing crude oil. These oil and gas industry deaths were in small firms in Texas, Oklahoma, and Rocky Mountain states. Thirteen deaths were in a variety of other circumstances.

\section{SOLVENTS}

Of the 35 deaths that could be attributed to solvents, 24 were from chlorinated hydrocarbons and 11 from naphtha, toluene, gasoline, diesel fuel, isopropanol, and coal tar pitch volatiles. Nine of the 35 deaths occurred in degreasing apparatus, eight in basements or pits below floor level in a plant area where solvents were used, and six in storage tanks. Five deaths were in employees who entered a tanker truck to clean it after transporting solvents and seven in other circumstances.

\section{HYDROFLUORIC ACID}

Three of the four deaths due to hydrofluoric acid involved maintenance operations in which the employee was sprayed with acid while unclogging a line or pump. In the fourth case an employee stepped on a five gallon bucket of hydrofluoric acid, his foot went through the cover, and he was splashed on the legs and abdomen. Three deaths occurred from cardiac arrest, two of them within minutes of exposure. In the fourth case the time and manner of death were not noted in the report.

\section{SUBSTANCE ABUSE}

Five deaths were definitely related to substance abuse, and a sixth case was questionable. Four occurred from recreational inhalation of nitrous oxide at work. T中. of these were restaurant workers who inhaled gass ordinarily used to power whipped cream dispenserf. One worker sniffing a can of methyl chloroform (1- $\mathrm{e}_{1}$ trichloroethane) used for cleaning was found de with his face over the open can. He had been recenthy hired and, unknown to the employer, had a history@f drug abuse. The sixth case was a truck driver who wos found dead in his cab, with the windows closed, with an empty can of Freon beside him. The death was presumed to be from inhalation but it is unknow whether this was intentional.

\section{RESPIRATOR DEATHS}

There were 14 deaths in which respirators werefa factor: two in confined spaces, one in a rescueq, occurred when a self contained breathing apparatus ran out of air. Two other deaths involved the use $\vec{\delta} f$ half face respirators with organic vapour absorbing cartridges in an oxygen deficient atmosphere, instead of self contained breathing apparatus. One worker using an air supplied respirator while sandblasting 率e inside of a tank died when the air supply hose came loose.

Nine deaths were due to improper air supply. Foọr involved hooking up a respirator to a nitrogenolime instead of to air. In one case the nitrogen line painted the same colour as a nearby air line. In other deaths the lines were not marked and in the fourth case the type of marking was not noted in the report. A fifth death occurred when a worker attached the air line of his respirator to an unmarked argon lirer. In all of these cases the same size fitting was used for. air, nitrogen, and argon lines. Four deaths were from carbon monoxide in which respirators were supplied with air contaminated with carbon monoxide from the exhaust of a compressor motor.

\section{Discussion}

The number of deaths found in this study from asphyxiation and poisoning (423) was selected from only those incidents that were investigated by OSHA in 47 states in a three year period. The average number of deaths for this period in the OSHA database was 1585 a year. The actual number of work related deaths in the United States in these years is not clear, with the BLS reporting 3740 for $1984,{ }^{4}$ and NIOSH reportifg 6258 based on death certificate data. ${ }^{16}$ In any case, OSHA investigated half or less of all work related deaths. Probably, therefore, the number due $\widetilde{f o}^{\circ}$ asphyxiation or poisoning during this period was greater than 423. 
The proportion of all work related deaths found in this study to be due to asphyxiation or poisoning $(8.9 \%)$ is similar to the findings of most previous reports. ${ }^{78}$ One exception is the Swedish death data which are not comparably coded. For industry groups, $37 \%$ of the deaths were in manufacturing, the same as reported in the NIOSH criteria document on confined spaces. ${ }^{17}$ The number found in oil/gas $(11 \%)$ and utilities $(5 \%)$ were higher than in the NIOSH report. Previous studies have not reported high rates of asphyxiation in these two industries.

Almost all of the victims were men. The same trend was seen by McCarthy and Jones for deaths from gassing and was attributed to differences in exposure by sex in the occupations at risk. ${ }^{10}$ There may also be differences in the degree of risk that is considered acceptable by men.

Although the mean age of the total group was relatively young (34.2 years), those who died from inhaling solvents were significantly younger than those who died from other causes. In the two reports of solvent toxicity cases in Britain there was a relative excess of younger cases and these were more severely affected. Perhaps certain tasks with heavy exposure to solvents, such as tank cleaning or operating a degreaser, involve more younger workers. Whether the increased number of deaths from solvents in younger workers are due to differences in exposure, susceptibility, or other factors deserves further investigation.

The 42 mechanical asphyxiations illustrate the danger of standing or working above stored grain, sand, or other loose materials. Although this hazard has been described before, ${ }^{18}$ the magnitude of the problem has not been noted. Since much of agricultural work is exempt from OSHA investigation, the number of asphyxiations involving grain could be much higher.

The NIOSH criteria document on confined spaces also studied the OSHA database and found 143 deaths, or 71.5 a year, for $1976-7 . .^{18}$ In the present study, for 1984-6, there were 146 deaths in confined spaces, or 48.7 a year, a decline of $32 \%$. This decline may be real or may be due to inclusion of deaths from causes such as electrocution or fire in the earlier figure. Another NIOSH report found $60 \%$ of deaths to be in rescuers. ${ }^{19}$ As six of the eight incidents discussed were multiple death accidents, these may reflect a tendency of NIOSH to investigate notorious events that would tend to have a high proportion of injured rescuers. A more recent NIOSH guide gave a figure of $50 \% .{ }^{20}$ Both are higher than the $12 \%$ found in the present study.

The high death rates in the oil and gas industry reflect exposure to the long recognized hazard of hydrogen sulphide released from high sulphur content crude oil. ${ }^{20}$ Deposits of "sour crude" are concentrated in the western United States and Canada where oil field workers are exposed in pits, fracturing tanks, and pumping operations. A review of $\mathbf{H}_{2} \mathrm{~S}$ poisoning in Alberta, Canada, found a $6 \%$ death rate in workers who had become ill as a result of exposure to $\mathrm{H}_{2} \mathrm{SS}^{21}$ Hydrogen sulphide has a foul odour, but at levels over $150 \mathrm{ppm}$ causes olfactory paralysis, with no warning to the worker of the hazardous atmosphere. ${ }^{22}$

Death from $\mathrm{H}_{2} \mathrm{~S}$ poisoning has also been observed, as it was in this study, among those who work in sewers. ${ }^{23} 24$ Manholes and sewers are classic examples of confined spaces where gas from sewage decomposition can accumulate in high concentrations. As in oil field workers immediate olfactory paralysis eliminates warning and is followed rapidly by loss of consciousness.

Hydrofluoric acid burns have been reported to be frequent, with rare deaths. ${ }^{25}$ The four cases investigated by OSHA all had exposures of large areas of the body. In the three cases involving work unclogging pumps and lines inadequate waterproof protective clothing was worn to protect the employee when a spray of liquid struck him full force. For any skin contact with hydrofluoric acid, immediate treatment with calcium gluconate, as a topical gel or by injection, is necessary, ${ }^{26}$ which was not done or was delayed in these cases.

Previous studies have emphasised that a proper type of air supply respirator should be used in oxygen deficient atmospheres and not cartridge type respirators. From the data presented here it appears that improper air supplies, such as pure nitrogen, or air contaminated by carbon monoxide, are as lethal as the choice of the wrong respirator. Special attention should be paid to avoiding the use of compatible fittings on lines supplying air for breathing and those with other gases. Intakes of compressors for air supply should be isolated from any motor exhaust.

This study has reported deaths from asphyxiation in the United States workforce for a three year period. The OSHA investigations cover less than half the work related deaths in the United States and certain groups such as agricultural workers are underrepresented. Nevertheless, the OSHA database is population based (47 states) and allows us to make some inferences about work groups at risk. Utility workers entering manholes and oil field workers in fracturing tanks appear to have the highest risk of asphyxiation. The previously reported finding that young workers are disproportionately affected by solvents has been confirmed in this study but is still unexplained. A study of morbidity data may provide sufficient cases to see if the excess in young workers appears more in those solvents favoured for drug abuse.

Although the OSHA IMIS database contains little information on the level of exposure to chemicals in 
these fatal accidents, or on the treatment of victims after exposure, the information available has provided a useful picture of the circumstances of fatal asphyxiation and poisoning.

We thank William Cloe, Joseph Dubois, Thomas Tyburski, and Bruce Beveridge of OSHA for providing the data on deaths and much helpful information. Karl Chen of the DuPont Corporation reviewed the manuscript and gave us background information.

\section{References}

1 Thackrah CT. The effects of principal arts, trades, and professions, and of civic states and habits of living, on health and longevity. Philadelphia: Henry Porter, 1831:83.

2 Clark I, Drinker P. Industrial medicine. New York: National Medical Book Company, 1935:199-201.

3 Eastman C. Work accidents and the law. Philadelphia: Russell Sage Foundation, 1910:49-57.

4 US Department of Labor, Bureau of Labor Statistics. Occupational injuries and illnesses in the United States by industry, 1984. Bulletin 2259, 1985; table 10, 49.

5 National Safety Council. Accident facts. Chicago: NSC, 1986:80.

6 National Board of Occupational Safety and Health. Occupational injuries in Sweden 1983. Stockholm: NBOSH, 1986:28.

7 Research and Planning Division. Labour indicator peninsular Malaysia 1983. Kuala Lumpur: Ministry of Labour, 1984: table 64.

8 Health and Safety Executive. Deadly maintenance, a study of fatal accidents at work. London: HMSO, 1985:19.

9 Bakinson MA, Jones RD. Gassings due to methylene chloride, xylene, toluene, and styrene reported to Her Majesty's Factory Inspectorate, 1961-80. Br J Ind Med 1985;42:184-90.

10 McCarthy TB, Jones RD. Industrial gassing poisonings due to trichloroethylene, perchlorethylene, and 1-1-1 trichloroethane, 1961-80. Br J Ind Med 1983;40:450-5.

11 Parkinson DK, Gauss WF, Perper JA, Elliott SA. Traumatic workplace deaths in Allegheny County, Pennsylvania, 1983 and 1984. J Occup Med 1986;28:100-2.

12 Colorado Department of Health. Colorado population-based occupational injury and fatality surveillance system report 198 (2) 1984. Denver: CDH, 1988:62.

13 Bureau of the Census. County business patterns 1984. Washingto US Department of Commerce, 1986:92. (CBP-84-1.)

14 Suruda AJ, Smith G, Baker SP. Deaths in the constructiou industry from trench cave-in. J Occup Med 1988;30:552-5.

15 Cloe WW. Selected occupational fatalities related to toxic af asphyxiating atmospheres in confined work spaces as found iw reports of OSHA fatality/catastrophe investigations. Washing ton: Office of Data Analysis, US Department of Labor, OSHA 1985:5.

16 Division of Safety Research. National traumatic occupationgl fatality study. Morgantown, West Virginia: National Institute for Occupational Safety and Health, 1987.

17 National Institute for Occupational Safety and Health. Criteria a recommended standard .. working in confined spaces. Cincim nati: NIOSH, 1986. (Publ No 86-110.)

18 National Institute for Occupational Safety and Health. Preventin entrapment and suffocation caused by the unstable surfaces stored grain and other materials. Cincinnati: NIOSH, 198\% (Publ No 88-102.)

19 Pettit T, Linn H. A guide to safety in confined spaces. Cincinnat National Institute for Occupational Safety and Health, 1987:12. (Publ No 87-113.)

20 Aves $\mathrm{C}$. $\mathrm{H}_{2} \mathrm{~S}$ poisoning in Texas. Texas State Journal of Medicina 1929;30:761-6.

21 Burnett WW, King EG, Grace M, Hall WF. Hydrogen sulfige poisoning: review of 5 years' experience. Can Med Asseg 1977;117:1277-80.

22 Hamilton A, Hardy HL. Industrial toxicology. 4th ed. Bostont John Wright, 1983:189-92.

23 Breysse P. Death in a hole. Occupational Health News\&uts 1963;11:95-7.

24 Adelson L, Sunshine I. Fatal hydrogen sulfide intoxication Pathol 1966;81:375-80.

25 Chan KM, Svancerek WP, Creer M. Fatality due to hydroflư⿱ acid exposure. Clin Toxicol 1987;25:333-9.

26 Bracken WM, Cuppage F, McLaury RL, Kirwin C, Klaassen C क्षि Comparative effectiveness of topical treatments fof hydrofluoric acid burns. J Occup Med 1985;27:733-9. 